82. Williams CT, Grier SA, Marks A. "Coming to Town": the impact of urbanicity, cigarette advertising, and network norms on the smoking attitudes of black women in Cape Town, South Africa. J Urban Health 2008;85:472-85.

83. National Cancer Institute. The Role of the Media in Promoting and Reducing Tobacco Use. Tobacco Control Monograph No. 19. Bethesda, MD: U.S. Department of Health and Human Services, National Institutes of Health, National Cancer Institute, NIH Pub. No. 07-6242, 2008

84. Greaves L, Johnson J, Bottorff J, et al. What are the effects of tobacco policies on vulnerable populations? A better practices review. Can J Public Health 2006b;97:310-15.

85. Godfrey C, Rice N, Slack R, et al. A Systematic Review of the Effects of Prices on the Smoking Behaviour of Young People. Public Health Research Consortium, 2010. http://www.york.ac.uk/phrc/papers.htm

86. Chaloupka FJ, Straif K, Leon ME. Effectiveness of tax and price policies in tobacco control. Tob Control 2010:20:235-8.

87. Tong EK, Tang H, Tsoh J, et al. Smoke-Free policies among Asian-American women: comparisons by education status. Am J Prev Med 2009;37(Suppl 2): S144-50.

88. Akhtar P, Currie D, Currie C, et al. Changes in child exposure to environmental tobacco smoke (CHETS) study after implementation of smoke-free legislation in Scotland: national cross sectional survey. Br Med J 2007;335:545.

89. NHS Information Centre. Statistics on NHS Stop Smoking Services: England, April 2009-March 2010. NHS Information Centre, 2010. http://www.ic.nhs.uk/webfiles/ publications/Health\%20and\%20Lifestyles/ SSS2009_10_revised.pdf

90. Nichter M, Nichter M, Padmawati S, et al; Project Quit Tobacco International Group. Anthropological contributions to the development of culturally appropriate tobacco cessation programs: a global health priority. In: Hahn R, Inhorn M, eds. Anthropology and Public Health: Bridging Differences in Culture \& Society. Oxford: Oxford University Press, 2009.

91. WHO. WHO Report on the Global Tobacco Epidemic, 2009: Implementing smokefree environments. Geneva: World Health Organisation, 2009.

92. $\mathbf{N g ~ N}$, Prabandari YS, Padmawati RS, et al. Physician assessment of patient smoking in Indonesia: a public health priority. Tob Control 2007:16:190-6.
93. Mohan S, Pradeepkumar AS, Thresia CU, et al. Tobacco use among medical professionals in Kerala, India: the need for enhanced tobacco cessation and contro efforts. Addict Behav 2006;31:2313-18.

94. Dozier AM, Ossip-Klein DJ, Diaz S, et al. Tobacco use in the Dominican Republic: understanding the culture first. Tob Control 2006;15:30-6.

95. Yang G, Fan L, Tan J, et al. Smoking in China. Findings of the 1996 National Prevalence Survey. JAMA 1999;282:1247-53.

96. Elton-Marshall T, Fong GT, Zanna MP, et al. Beliefs about the relative harm of 'light' and 'low tar' cigarettes: findings from the International Tobacco Control (ITC) China Survey. Tob Control 2010;19(Suppl 2):i54-62.

97. Ho MG, Ma S, Chai W, et al. Smoking among rural and urban young women in China. Tob Control 2010;19:13-18.

98. Bhanji S, Andrades M, Taj F, et al. Factors relating to knowledge and perception of women about smoking: a cross sectional study from a developing country. BMC Womens Health 2011;11:16.

99. Chomba E, Tshefu A, Onyamboko M, et al. Tobacco use and secondhand smoke exposure during pregnancy in two African countries: Zambia and the Democratic Republic of the Congo. Acta Obstet Gynecol Scand 2010;89:531-9.

100. Petersen Z. Smoking Cessation During Pregnancy: A Person-centred Approach Among Disadvantaged Women in South Africa [Ph.D. dissertation]. Sweden, Department of Public Health and Clinical Medicine, Epidemiology and Global Health Umea University, 2011.

101. Greaves L, Jategaonkar N. Tobacco policies and vulnerable girls and women: toward a framework for gender sensitive policy development. J Epidemiol Community Health 2006;60:ii57-65.

102. Richardson L, Greaves L, Jategaonkar N, et al. Rethinking an assessment of nicotine dependence: a sex, gender and diversity analysis of the Fagerstrom test for nicotine dependence. J Smok Cessat 2007:2:59-67.

103. Greaves L, Hemsing N. Sex, gender, diversity and second-hand smoke policies: implications for disadvantaged women. Am J Prev Med 2009;37(Suppl 2):S131-7.

104. Nichter M. Introducing tobacco cessation in developing countries: an overview of Project Quit Tobacco International. Tob Control 2006;15(Suppl 1):12-17.

105. Pathania VS. Women and the smoking epidemic: turning the tide. Bull World Health Organ 2011:89:162.

\section{Women and tobacco: part of the bigger picture}

The article on women and tobacco by Amos et al provides a comprehensive overview of issues relating to the use of tobacco and the problems of tobacco control in girls and women. ${ }^{1}$ The authors highlight the problem of the more disadvantaged women in high income countries and the more complex situation with girls' smoking rates in low and middle income countries (LMICs).

However, the solutions suggested to the women's problems that are highlighted raise issues particularly in LMICs of where the often sparse tobacco control money should be preferentially spent. The authors state that the smoking rates in some developing nations are less than $5 \%$, but given that the regions mentioned where the estimated rates in women are Africa $2.8 \%$, Western Pacific 4.8\%, South East Asia 4.6\% and Eastern Mediterranean $4.4 \%$, and these are just a fraction of the male smoking rates, would it not be prudent in LMICs with limited resources to implement population-wide smoking measures rather than target a lower prevalence group?

The authors highlight the problem of targeting girls and women in marketing tobacco and rightly recommend implementation of the restrictions on industry marketing required by the Framework Convention on Tobacco Control (FCTC). ${ }^{2}$ They could have gone further and recommended wide implementation of plain packaging, which has just been passed by the Australian parliament and will not only prevent attractive packaging but prohibit small pack sizes with slim cigarettes
(FCTC Article 11). ${ }^{3}$ Also, over 40 countries are applying graphic health warnings on packs. These can be used to warn of the health risks of smoking, secondhand smoke and specific areas of concern about the risks of smoking during pregnancy and may be the most affordable way low income countries can embark on education, while spending their limited resources on more costeffective measures such as advertising bans.

The importance of price increases in reducing smoking prevalence is acknowledged by the authors but they indicate that the sale of single sticks can reduce the impact of this measure. Article 16.3 of the FCTC prohibits this and what needs to be stressed is the importance of multiple measures being introduced simultaneously rather than one measure at a time. With children at younger ages starting to smoke, less affordable cigarettes and plain packs with graphic warnings will be required together to address this issue.

In LMICs prioritising anti-tobacco measures to first implement those which will have the greatest impact is vital. While gender-sensitive measures to reduce secondhand smoke and achieve smoke-free homes is an important goal, the issue is whether in countries which have not yet fully implemented FCTC Article 8 to ensure public and work places are smoke-free, emphasis on smoke-free homes may provide a convenient excuse for governments to transfer the responsibility to individual smokers, when increasing numbers of women are in the workforce and protection of work and public places may be initially more effective for them.

Finally, the paper makes a strong case for more research: both quantitative and qualitative research at the individual, community and healthcare settings level. There is no doubt that this would be useful. However, this type of research is expensive 
and would not be affordable by many LMICs. Fortunately, the FCTC has laid out core cost-effective measures to be put in place. Once they have been achieved, governments will be better positioned to conduct this more detailed research, for which the authors rightly identify the need.

\section{lan N Olver}

Correspondence to Professor lan N Olver, CEO, Cancer Council Australia, GPO Box 4708, Sydney, NSW 2001, Australia; ian.olver@cancer.org.au

Competing interests None.
Provenance and peer review Commissioned; internally peer reviewed.

Tobacco Control 2012;21:243-244. doi:10.1136/tobaccocontrol-2011-050354

\section{REFERENCES}

1. Amos A, Greaves L, Nichter M, et al. Women and tobacco: a call for including gender in tobacco control research, policy and practice. Tob Control 2012:21:236-43.

2. Amos A, Haglund M. From social tobacco to "torch of freedom": the marketing of cigarettes to women. Tobacco Control 2000;9:3-8.

3. WHO Framework Convention on Tobacco Control: Guidelines for Implementation Article 5.3; Article 8; Articles 9 and 10, Article 11, Article 12, Article 13, Article 14. Geneva, Switzerland: WHO Press, 2011. 